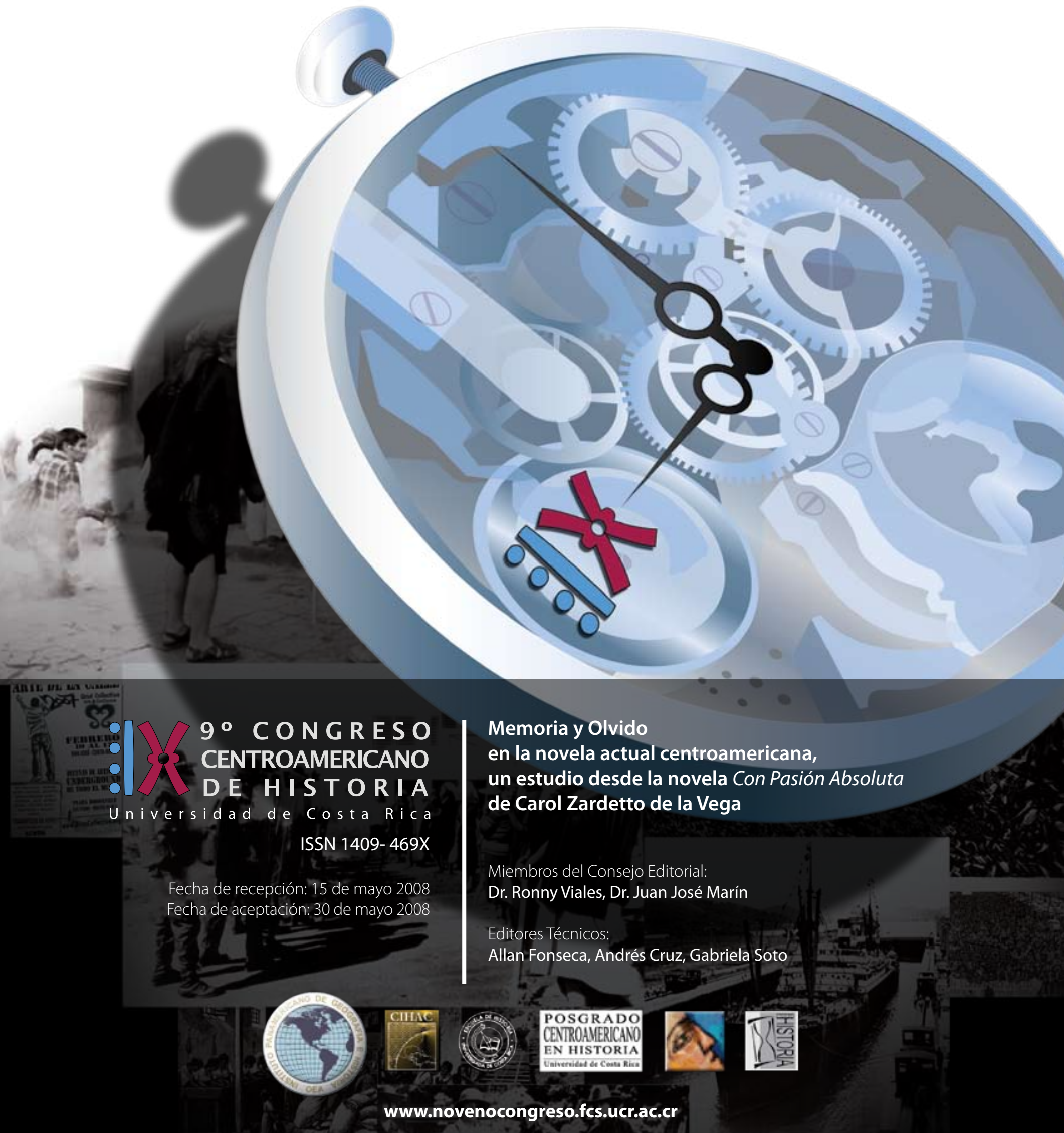


Indexaciones: Repositorio de Revistas UCR, DIALNET, Latindex, REDALYC Directorio y recolector de recursos digitales del Ministerio de Cultura de España, Directory of Open Access Journals. Diálogos Revista Electrónica de Historia ISSN 1409-469X. Número especial 2008. Dirección web: http://historia.fcs.ucr.ac.cr/dialogos.htm

\section{Memoria y Olvido \\ en la novela actual centroamericana, un estudio desde la novela Con Pasión Absoluta \\ de Carol Zardetto de la Vega}

Isabel Jara Quesada ${ }^{1}$

$1 \quad$ Bachiller en Filología Española, estudiante de la Licenciatura en Filología Española, en Literatura, y del Bachillerato en Historia, ambas por la Universidad de Costa Rica, ijaraq@yahoo.es 


\section{Introducción}

\section{Medacem memorem esse oportet}

La escritura es un recurso mnemotécnico que vierte sobre la hendidura de la forma las variaciones y conformaciones que la estructura mental convierte en palabra; al nombrar, al asignar un sentido (entendemos por sentido no a la recurrente forma doxológica, sino a la semiológica) a un hecho concreto, o específico, por ejemplo, a los pensamientos, a los sentimientos y a los recuerdos, la grafía pierde su total capacidad transmisora -si es que la tiene-, de modo que no existe una «fórmula» para descifrar los códigos envilecidos en un texto; no hay forma de adentrarse en el medio de su locura, nada más ingenuo que pretender 'entender' lo que ellos mismos, los signos, no entienden. ¿Es necesario entender algo?

La dificultad de la escritura ofrece un reconocimiento: «se la reconoce como 'personal', remitiendo al estatuto impenetrable del individuo»(2002: 91). Su dificultad prima sobre la intención de comunicar algo, ¿acaso el trazo debe comunicar algo? El intento fallido por la comprensión de la forma escrita es, con mucho, el mayor peligro; provoca que se pierda la con/ postura del placer; el mito de comunicar, trastorna los referentes y evoca la confusión, confusión con la que se corre el riesgo de romper el encanto de reordenar los sentidos. El mito es capaz de crear patologías.

De manera que escribir para comunicar algo no es más que una ingeniosa de forma de hacer perder el tiempo de todos, principalmente, el del lector, sencillamente, porque no existe vínculo posible entre el habla y la palabra; del pensamiento al trazo hay un espacio y un tramo en el que algo se pierde: recordamos para escribir, pero el olvido es el traidor de la trascripción del pensamiento. Siempre se pierde algo, siempre se queda debiendo algo, entre el sentido y la forma escrita, algo queda fuera, entre la memoria y el olvido surge una pugna Titánica, imposible 
de precisar su acuerdo o, en términos modernos, su concesión.

En los, llamados, géneros literarios abundan las formas con intencionalidad de traslacionar los pensamientos, todos y cada uno de ellos, a vertiginosas grafías y complicadas estructuras que, de alguna forma, buscan manifestar el sentido. Los llenan de tantas cosas que el sentido se confunde y se cree tener certeza de que el sentido es «este» $\mathrm{o}$ «aquel», cuando el sentido nunca es manifiesto sino latente. En el caso de la novela, el sentido no es exclusivamente bidimensional, a veces, puede ser tridimensional, como la banda de Moebius, pero no para crear metalenguajes; de ahí que existan tantas novelas como ubicaciones, la mayoría de ellas desafortunadas, cuando, en realidad, lo que existen son textos y sentidos.

Por lo anterior, se concibe a la escritura como la portadora del significado en una estructura que busca enriquecer el sentido y adiciona el sentido con diversos referentes, uno de los cuales puede poner en conflicto al lector y esto es lo verosímil.

La memoria y el olvido son dos de esos recursos de ubicación: uno es al otro como el otro es al uno, no es posible desasociarlos, su conjunción representan el acicate de variantes impregnadas en las construcciones que intentan hacer los escritores. Se recuerda para olvidar, y se olvida para volver a recordar. No importa qué, lo que interesa es el sentido de ese recuerdo.

Por eso, en este trabajo se pretende trabajar con estas dos ubicaciones: memoria y olvido esparcidas por un texto asignado: Con pasión absoluta, de la diplomática guatemalteca Carol Lilliana Zardetto de la Vega.

\section{Con Pasión Absoluta: argumento}

La novela Con Pasión Absoluta ${ }^{2}$ la encontramos vertida sobre la vida de varias generaciones

2 Carol Zardetto de la Vega, Con Pasión Absoluta _Guatemala, F\&G Editores, 2005). 
de mujeres, de una misma familia, en Guatemala desde finales del siglo XIX, principios del XX, hasta la década de los años noventa en el conflictivo territorio chapín; son una serie de sucesos que marcaron la vida de: mama Amparo, Victoria, la Nena e Irene, cada una va narrando sus experiencias y se inscriben apartados donde se suscitan los hechos políticos de los presidentes: Ubico, Arbenz y Ríos Montt, tres protagonistas fundamentales de la historia guatemalteca.

En el caso de mama Amparo, ubicada hacia 1930-1944, se recoge el apunte sobre la vida de una mujer que debe enfrentar la marginalización a raíz del nacimiento de un hijo con el hijo del patrón de una finca cafetalera que, aunque este quiere casarse con Mama Amparo, esta no acepta. Luego sigue Victoria, hacia 1955-1960, la hija de mama Amparo, que se convierte en maestra rural, lo mismo que la Nena quien se convierte en maestra y vive con Angel Ferrara, empresario cafetalero y casado. Finalmente, Irene, la hija de la Nena e hijastra de Angel Ferrara que, gracias a los ingresos de Ferrara, recibe una honrosa educación fuera de su país y que regresa para el sepelio de mama Amparo.

En síntesis, el argumento se desarrolla cuando Irene, efectivamente, regresa a Guatemala para los funerales de mama Amparo, después de vivir varios años en Canadá: "Me veo con los ojos del recuerdo. Mis pasos recorren otra vez el camino de regreso: soy testigo de mí misma. Estoy presente en ese momento al que escojo llamar 'entonces'. Y porque estoy 'presente' deja de ser pasado. ¿Qué juego es éste?” Pero Guatemala ya no es la misma: “No se vuelve nunca a lo mismo, ni somos ya los mismos. Las calles de mi infancia desaparecieron sepultadas bajo estas otras... Mi rostro de entonces desapareció también...”3

Irene va reconstruyendo, con recuerdos e imágenes, el pasado lleno de personas importantes para ella, por ejemplo: el salón de belleza de la tía Julia, Aura o las violetas, las actividades cotidianas de mama Amparo, algunas de las calles de Guatemala que no son las $3 \quad$ Ibid., 15. 
mismas por donde ella pasó; sin embargo, estos recuerdos van acompasados por el desafortunado ritmo de la historia política guatemalteca.

La trama va tejiéndose con el balance sobre la vida de la protagonista que vive de los recuerdos que le provoca una relación, atravesada por los devaneos del discurso de: 'amor imposible' desarrollado a través de una secuencia de viajes por diversos lugares de América: Vancouver, Nueva York, Lima, Montevideo, Buenos Aires, y en el que va intercalando los momentos en la vida de cada una de las mujeres citadas anteriormente.

\section{Con Pasión Absoluta: algunas generalidades sobre la autora}

Carol Lilliana Zardetto de la Vega es la escritora de esta novela; abogada, consultora en temas de combate a la corrupción y diplomática: fue Viceministro de Educación, en el gobierno de Álvaro Arzú en 1996, y Cónsul General de Guatemala en Vancouver, Canadá.

Entre sus muchos oficios, destáquese su trabajo como guionista de cine, crítica, comentarista de teatro, ensayista, poeta y cuentista, publicando su trabajo en Magna Terra y en el diario Siglo XXI; la novela Con Pasión Absoluta es su primera novela, la que firmó con el pseudónimo de Silke Zitar, a la que se le reconoció el premio: Mario Monteforte Toledo en el año 2004, primera mujer en lograr tal galardón ${ }^{4}$

\section{Con Pasión Absoluta: representaciones narrativas}

En lo tocante a personajes, en la novela Con Pasión Absoluta sobresalen cinco aspectos: primero, el que tiene que ver con la génesis y desarrollo de los personajes a los que se los define como 'estáticos y prefijados', es decir: «que aparecen ya configurados desde un principio y

$4 \quad$ Ibid., 1 
continúan invariables a lo largo de la obra» ${ }^{5}$, en este sentido, y tomando en cuenta que la trama se centra en la vida de tres generaciones de mujeres, podemos citar que tanto mama Amparo, la Nena e Irene son personajes que ya se han establecido desde un inicio, su estaticidad radica en que estos personajes no varían en la obra porque no suscitan un cambio inesperado en su participación, excepto en su estructura psicológica que, dadas las circunstancias, se transforman paulatinamente.

Segundo, por su grado de complejidad, los personajes en esta novela son 'planos', porque están fijados a dos cualidades específicas a lo largo de la trama: el desdén amoroso y el esfuerzo personal que converge asido al trabajo en la docencia, único recurso para promover una mejora sustancial en sus vidas.

Tercero, por la función desarrollada, se concibe a la protagonista como 'narrador testigo' no solo porque participa de la evolución en las vidas de quienes la rodean, sino que también presencia los hechos políticos de Guatemala. Cuarto, participan personajes 'colectivos', esto es, todas aquellas personas que fueron víctimas de los hechos políticos guatemaltecos.

Finalmente, y dada la puesta en acción, o escena, los personajes participan de acciones particulares y esas particularidades se articulan en ellos mismos, en ese sentido, encontramos a las tres mujeres participando, de una u otra forma, en procesos de la vida guatemalteca, v.gr: la visita a Ubico para pedir explicaciones sobre las responsabilidades del padre de la hija de mama Amparo; el asesinato de Angel Ferrara como resultado de los descalabros económicos provocados por el conflicto bélico guatemalteco, etc.

Los sucesos extratextuales representados en la novela Con Pasión Absoluta son, a todas luces, los hechos políticos vividos en Guatemala desde el presidente Ubico hasta la firma del acuerdo de paz en 1996; el lenguaje de la novela es culto, en los apartados donde se presenta la $5 \quad$ Ibid., 370. 
descripción de sucesos tanto de los personajes como del país, y es popular en los tramos donde los personajes hablan utilizando expresiones como: 'vos sabés lo que hacés'; 'yo me llevo a los patojos'; 'andáte a la esquina donde están las que son como vos', etc.

Por lo que toca al tema de paratexto, Con Pasión Absoluta, como libro, cuenta con una fotografía en la portada que refiere a una mujer, en apariencia crucificada, llevando una corona de flores y el título que surge como un juego de palabras, debido a que la última línea de la novela es: «la vida merece compasión absoluta». Estos referentes gráficos, en términos de edición, nos llevan a una salida engañosa, ya que podría suponerse que el texto está orientado a un tema erótico o romántico, cuando la centralidad del texto es otra.

Aún cuando el texto contenga un capítulo que describe los infortunios amorosos de la protagonista, no tiene, desde su contenido, una relación directa con la portada. Ingenuamente, podría decirse que es 'el sacrificio de una mujer', o, 'la agonía del desamor', o cualquier otro lugar común en el que se somete a las mujeres en la literatura, cuando lo cierto es que, por los temas que se abordan en la novela, es posible suponer que haya sido necesario darle al texto, como libro, un lugar de consumo, una especie de 'enganche' que no afecte sensibilidades políticas guatemaltecas, toda vez que su escritora estuvo vinculada al poder cuando este recibió las declaraciones del informe Memoria del Silencio del que se hablará más adelante.

Además, la estructura del texto, en tanto párrafos, está presente una alternancia de un hecho en el presente o en el recuerdo, intercalado por un hecho en el pasado de los personajes o de Guatemala.

\section{Memoria y olvido}

En la Teogonía de Hesíodo, aparece una de las conformaciones mitológicas más atrayentes: 


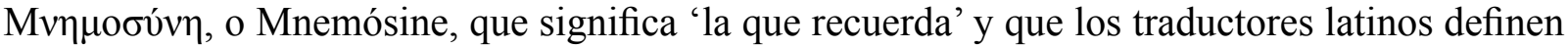
como 'memoria', es la Titánide que, desposada por Zeus, concibe a las musas, pero que es confrontada por $\Lambda \eta \tau \omega ́$, o Leto, que significa 'la oculta', por la predilección que siente Zeus hacia sus hijas, mientras que a los de Leto, el dios no los toma en cuenta. Los celos de Leto son tan grandes que constantemente busca perturbar a Mnemósine y con ello a sus hijas ${ }^{6}$.

La labor de Leto es estar atenta el rapto de las musas, es decir, al preciso momento en que el mortal se inspira o recuerda algo que le provoque trabajar, para interponerse y hacer que éste olvide por completo lo que recordó o lo que lo inspiró. ${ }^{7}$

Esta lucha entre las titánides es perenne: Mnemósine siempre será boicoteada por Leto, ésta nunca permitirá que la memoria persista, constantemente la abordará para impedir que el dios esté contento con ella. Por ello, para los griegos era muy importante la memoria, sin ella la persona estaría perdida.

Luego, los latinos de la República Romana tomarán estos criterios para incorporarlos al Iudex Romanus estableciendo que 'měmŏrare', o conmemorar, fuera un imperativo en la población romana, es decir, que se ubicara a un hecho importante dentro de la cotidianidad del pueblo; así, todas las formas de expresión del héroe romano o de los triunfos de la República estarían versados en la conmemoración en una fecha específica, cultivando su resonancia en un espacio dentro del calendario. Por oposición a la conmemoración está el 'oblitare' que por el participio 'oblivisci' refiere, literalmente a 'olvidar las injusticias', esto supone que existen acontecimientos que el pueblo romano no concebirá con beneplácito, deberán ser olvidados, no ha habido justicia posible para ellos, de ahí que se los olvide, pero ¿cómo se sostiene ese olvido?,

6 Susana Cañuelo y Jordi Ferrer Mitología griega y romana, (España: Editorial Optima, 2003).

7 Libreros Editores, Enciclopedia de la mitología, (Madrid: Afrodisio Aguado, S.A., 1967). 
¿es posible olvidar?, ¿dónde acaba la memoria y dónde empieza el olvido?

Si queremos saber qué es memoria en la literatura, debemos buscar en la literatura su definición; es en ella, y sólo en ella, donde encontramos las concepciones que priman, aunque existen supuestos establecidos y conformados por argumentos teóricos, no pasan de ser una constitución de metalenguajes que nunca ven el ocaso.

Así que buscamos las definiciones que da la literatura sobre memoria; en Confesión $\mathrm{X}$, San Agustín plantea: «El presente mirando el pasado es memoria, el presente mirando el presente es la percepción inmediata, el presente mirando el futuro es expectativa» ${ }^{9}$, la perspectiva agustiniana de la memoria es la respuesta a la conformación de un apartado en la vida anímica de los sujetos que permite visualizar los hechos como un todo, amalgamados por la consolidación del tiempo; la memoria es la vitalidad misma, presente en el pasado, en el presente mismo y en la esperanza; la confrontación de la memoria es el tormento examine que agota todas las opciones que puede tener el ser humano: su recuperación consiste en lo manifiesto, en lo que identifica a cada ser humano con el hecho mismo de la memoria, no en la saturación de recuerdos, sino en la paulatina separación de ellos, definir aquel hecho significativo y revisarlo. Ese continuo examen es, con mucho, el que orienta la interpretación de la memoria, de ahí su expectativa.

Más adelante, Jorge Luis Borges, en La Memoria de Shakespeare, nos dice que la escritura y la lectura son dos ejercicios de la memoria y el olvido ${ }^{10}$; Roland Barthes, en $S / Z$ y en Variaciones sobre la escritura, señala: «A la escritura la penetra muy pronto un simbolismo secundario: siendo "grafismo", orden de la pura memoria, se convierte en "escrituras", campo de

8 Joan Corominas, Breve diccionario etimológico de la lengua castellana, (España: editorial Gredos, 2005)

9 San Agustín, Confesiones, (España: Edicomunicaciones S.A, 2001), 18.

10 Jorge Luis Borges, La memoria de Shakespeare, (Buenos Aires, Argentina: Alianza Editorial, 2004). 
la significación infinita (...) Leo porque olvido». ${ }^{11}$

Finalmente y, en Así hablaba Zaratustra, F. Nietzsche propone, también, ejercicios de la memoria, pero no atravesados por la escritura o la lectura, sino sobre los hechos mismos. Nietzsche señala que frente al recuerdo acumulado, es decir, ante el 'tonel de memoria', existe un arte, y ese arte es un ejercicio, y este ejercicio es el del olvido, de modo que la memoria no puede accederse sola, necesita de un arte, de un juego artístico o un arte del juego, y ese es el doble juego del recuerdo y olvido ${ }^{13}$. Ese juego es el de la oscilación y es esta propuesta de la literatura la que nos interesa destacar.

La memoria es la oscilación entre el recuerdo y el olvido; el recuerdo es el préstamo que le hace la conciencia a la palabra y el olvido es el recurso mediante el cual el sentido, su significado, entra en crisis. La oscilación surge de una masa, de una especie de ameba mental, que se acurruca en las cuencas de los pensamientos, de la psique si se quiere, que va y viene diligentemente, cruzando un puente, un pasillo, una puerta, en donde en un extremo está el recuerdo y en el otro el olvido; es un ir y venir que no es posible retener, contener; sin prisas ni contratiempos esa oscilación puede hacerse palabras: dichas y no dichas. Las dichas son eso dichas, las no dichas, con regularidad, son soñadas, o escuchadas. Puede decirse que el mayor deleite de la oscilación es vacilar, promoviendo en el sujeto una angustia, un no saber qué es, pero que está ahí y que mortifica, que incomoda y que, por tanto, debe salir.

Recordar es 'despertar', quizás de un sueño, de un letargo o de esa posición que nos atrapa y que decimos es un soñar despiertos, de ahí que nos sorprendamos diciendo: «es que me estaba acordando de algo»; con frecuencia nos parece que no es exacto lo que decimos de lo que nos estábamos acordando, nunca es lo mismo, vacilamos y es necesario revolver y revolver 11 Roland Barthes, Variaciones sobre la escritura, (Barcelona: Paidós, 2002) 18.

12 Roland Barthes, S/Z, (Argentina: Siglo XXI editores, 2004), 7.

13 Friedrich Nietzsche, Así habló Zaratustra, (Madrid: Alianza Editorial, 2000), 194. 
para tratar de definir aquello que recordamos. ${ }^{14} \mathrm{Y}$ a veces, es imposible, no lo conseguimos; aquello que nos mortifica, que nos incomoda, que no sabemos qué es, pero que debemos sacarlo es insuficiente en palabras. Es aberrante y, quizás por eso, olvidamos. El olvido, suele ser, una salida propicia, nos toma un poco de tiempo decidirnos, pero lo hacemos, estrepitosamente, olvidamos, salimos.

El olvido: «no es lo mismo el olvido en el sentido de desconocimiento del pasado, que olvido en el sentido de no dar importancia al pasado. En el primer caso el olvido es ignorancia y, en el segundo, injusticia» ${ }^{15}$. El olvido es la mejor manera, o modo, con el que nos podemos desprender de aquello que desconocemos, que no tenemos certeza de saber qué es; ignoramos con gusto, porque nada más molesto que convivir con ese recuerdo que no podemos definir, pero más molesto todavía cuando lo identificamos, lo definimos, o por lo menos nos aproximamos a su definición. Al hacerlo, nos sorprende que el sentido que damos a esa definición, su significado, suele ser abrupto, abusivo, y por eso, lo ignoramos, porque esa amnesia voluntaria, ese rechazo, nos permite no responsabilizarnos de las consecuencias, no importan las circunstancias, simplemente salimos a la calle, tiramos todo, incluso la llave de la puerta principal. Salir, el mejor, acaso el único motivo para invisibilizar nuestra impotencia para reconocer ${ }^{16}$.

El recuerdo y el olvido forman parte de una estructura que no admite separación alguna, actúa sobre sí y no acepta la ausencia de ninguno de sus componentes, de ahí la oscilación; si alguno de los dos no está presente, esa misma estructura se mueve, se desplaza, como ameba mental, para reorganizarse, para seguir; la oscilación advierte ese acomodo y participa de él, 14 Mónica Cragnolini, "Memoria y olvido: los avatares de la identidad en el entre”. Escritos de Filosofía, Academia Nacional de Ciencias, Buenos Aires, 2000. Disponible en: http://www.nietzscheana.com.ar/memoria olvido.htm (Fecha de acceso: 17 de octubre 2007).

15 Jorge Semprún, "La memoria como escritura", Letras libres internacional. Madrid, 2003. Disponible en: http://letraslibres.com (Fecha de acceso: 13 de octubre de 2007).

16 R Mate, "Memoria e historia: dos lecturas del pasado". Letras Libres Internacional, Madrid, 2003. Disponible en: http://www.letraslibres.com (Fecha de acceso: 23 de agosto de 2007). 
contribuyendo a que ninguno de los dos se extravíe. La vitalidad de la oscilación está ahí: en no permitir la separación del recuerdo y del olvido. ${ }^{17}$

\section{Memoria y Olvido en Guatemala}

El siglo XX es el siglo de la imagen del horror. Hasta entonces, los hechos dolorosos habían sido narrados como episodios de heroísmo construido por ideales que buscaban la libertad absoluta sobre los imperios existentes, nos referimos con esto al caso particular de América Latina. Sin embargo, diez años después de iniciado la vigésima centuria, México inició el recuento de violencia sustentada en principios de igualdad efectiva; los bolcheviques lo hicieron siete años más tarde en Rusia y la Primera Guerra Mundial iniciaba la escalada hacia una ruta de desolación para el mundo.

Después de la Segunda Guerra Mundial, dos porciones del macizo continental europeo quedaban sesgadas por posturas ideológicas abiertamente opuestas: el fascismo y el socialismo. Alemania sería el primer país en frecuentar los pasillos de la oscilación; el tonel de memoria sería incontenible y por ello era preciso olvidar. Romper con el pasado bélico alemán, implicó rodear al pueblo de un silencio: no se diría nada los próximos veinte años. ¿La razón?, habría sido imposible creer en los volúmenes de violencia propiciados por un grupo, luego, las consecuencias de este grupo caerían en el resto de la población y, después, en las futuras generaciones ${ }^{18}$.

Europa del Este corrió con la misma suerte: se desvinculó del nazismo para caer en las manos del socialismo extremo. Los campos de concentración dejaron de funcionar con la

17 S. a. "Memoria contra olvido". Grupo de recuperación de la memoria libertaria Valladolid. CGT, 2000. Disponible en: http://www.memorialibertaria.org/IMG/doc/Memoria_contra_olvido.doc (Fecha de acceso: 23 de agosto de 2007).

18 B. Groppo, "Memoria y olvido del pasado nazi en la Alemania de la Segunda Guerra Mundial”._. CESMOS, 2002. Disponible en: http://memoria.com.mx/node/617 Web Master: no disponible. (Fecha de ingreso: 17 de octubre de 2007) 
naturaleza práctica de su uso, pero siguieron siendo sitios seguros para albergar a aquellos que no estuvieran de acuerdo con los planes del régimen stalinista.

La memoria de estos lugares sería erguida en monumentos inverosímiles, como el Valle de los Caídos en España, donde el espectador confunde a la víctima con el victimario. ${ }^{19}$ En 1990 en Francia, se buscará subsanar los recuerdos del pasado creando un reconocimiento histórico para las víctimas del genocidio armenio en 1915; el resultado fue la aprobación absoluta de aquellos que creyeron en que se debía recuperar algo, para volverlo a olvidar.

Mientras eso sucedía en Europa, en América Latina apenas se iniciaba el recuento de los daños; lo que empezó como rumores de comunistas malhumorados, de indígenas mentirosos y de resentidos sociales, se convirtió en uno de los mayores desconciertos para el mundo: cientos de desaparecidos, torturados, mutilados, asesinados, exiliados, perseguidos en toda la franja continental, empezaron a salir de las trincheras en las que permanecieron enmudecidos; como espectros de los más inverosímiles cuentos de horror, dejaron las fosas comunes y se pegaron a las fotografías, a las cintas de video en documentales, a las narraciones testimoniales, en crónicas de prensa -en los lugares donde todavía la prensa tiene claro su compromiso profesional-, se pegaron a entrevistas, a cuentos, a novelas...

Vaciados de expresiones humanas, los restos de la población civil, sobreviviente, comenzaron a desgranarse como mazorcas de maíz: grano por grano fueron hilándose conclusiones, hipótesis, suposiciones, iniciaron la caminata por montañas, desiertos, antiguos caseríos, todos buscaban respuestas para sus preguntas, que son siempre las mismas: ¿no lo ha visto, llevaba un güipil púrpura? Las frases con las que inician sus relatos son casi iguales: «la última vez que los

19 Ana Nuño, "La Batalla por la memoria y el olvido de la historia" Letras libres internacional, Madrid,2006. Disponible en: http://letraslibres.com (Fecha de acceso: 10 de setiembre de 2007). 
vi...», «cuando llegaron los oficiales...» $»^{20}$

En América Latina no existe un solo país que no haya experimentado la persecución y la guerra fratricida, incluso en Costa Rica, pero aquí el asunto es más bucólico: en 1948 se mató gente, entre todos, lo más arrebatador es que después se nos engalanamos de caudillo y con todo y caudillo se quitó el ejército; en seguida se construyó un Museo, o lo que es lo mismo una Galería de Fantasmas, que luego fue condecorado, en 1987, con una medalla de la paz.

Argentina, Chile, Uruguay, Paraguay, Perú, Panamá, El Salvador, Nicaragua, todos participaron de diversas maneras de esas formas de violencia; años después, a todos los países se les exigió respuestas. Unos lo hicieron paulatinamente, otros a medias. En algunos, los dictadores fueron nombrados 'senadores vitalicios' o, en otras palabras, celadores del bien supremo, ayudados por el unánime: «No tenemos por qué aceptar que un país se haga marxista por la irresponsabilidad de su pueblo» ${ }^{21}$, frase que también ganó una conmemorativa medalla de la paz. Países que tuvieron que esperar otros diez o quince años para obtener respuestas, como el caso de Chile y Argentina, donde las Madres de la Plaza de Mayo no volverán a caminar.

En Centroamérica el caso no es particular, Guatemala tuvo que recurrir al auxilio extranjero para que se reconociera que una parte de su geografía contenía muchísimos seres humanos. Guatemala buscaba respuestas, muchas personas querían saber por qué sus familiares no habían vuelto a casa, necesitaban cerrar algo que les fue abierto con violencia y que, hasta ahora, no había forma de cerrar.

Por eso, y bajo el acuerdo de Oslo en 1994, se fundó la Comisión para el Esclarecimiento

20 Mauricio Fernández Picolo, 2002. "La rebelión de la memoria", Revista Chiapas, Era-ILLEC México, 2002. Disponible en: http://membres.lycos.fr/revistachiapas/, y http://www33.brinkster.com/revistachiapas (Fecha de ingreso: 11 de setiembre de 2007).

21 H, Montealegre, "La dictadura militar chilena 1973-1990", Santiago de Chile, 1995. Disponible en: http://. www.derechos.org/nozkor/chile/libros/memoria/a.html. (Fecha de acceso: 11 de setiembre de 2007) 
Histórico para constatar con objetividad, equidad e imparcialidad: «las violaciones a los derechos humanos y hechos de violencia que han causado sufrimiento a la población guatemalteca, vinculados con el enfrentamiento armado"22. En un informe llamado: Memoria del Silencio y en el Teatro Nacional de aquel país, el 25 de febrero de 1996 Guatemala supo lo que había sucedido; el nombre de Monseñor Gerardi arrancó los primeros recuerdos y la revelación de los hechos fue recrudeciendo el recuento de los hechos. Más de 200 mil seres humanos habían perdido la vida enfrentando los más inimaginables vejámenes; el ensañamiento contra la población civil, principalmente la indígena, fue brutal. ${ }^{23}$

Durante el gobierno de Ríos Montt se dan los principales acontecimientos: las operaciones 'tierra arrasada', que consistieron en rodear a una población entera, para desaparecerla después, así como la creación de la PAC, Patrullas de Autodefensa Civil, y la creación de las unidades de los Kaibiles fueron solo una parte de la conformación de equipos humanos especialistas en acabar con todo lo que no pensara igual. Acusaban a los indígenas de ser comunistas, cuando la mayoría sólo habla lengua quiché o cakchiquel, porque, en palabras de Ríos Montt: «los indígenas son la base de estos movimientos y por lo tanto, al ser sospechosos hay que matarlos a todos», eso explica -en parte- su aniquilación y su desplazamiento. ${ }^{24}$

Después de la lectura del informe, al presidente Arzú y a su gabinete les correspondió dar fe de lo dicho y llevar a cabo las acciones pertinentes; con un poco de pesadez para aplaudir ${ }^{25}$, el presidente Arzú se comprometió a tomar medidas, pero después se dijo que el informe no era tan imparcial y que había que tener cuidado con lo que decía, pues tal información podría

22 Comisión para el Esclarecimiento Histórico, CEH. "Informe: Memoria del Silencio". Ciudad de Guatemala, 1996. Disponible en: http://www.chr/aaat.org/guatemala/ceh/spanish/toc.html (Fecha de acceso: 09 de setiembre de 2007).

$23 \quad$ Ibid,. 13

24 Ibid, 18.

25 Ibid,.47. 
tener repercusiones en el turismo de Guatemala y así se hizo, la prensa, al igual que durante las dictaduras, tuvo su cuota de participación y del informe de la CEH nunca volvió a hablar. ${ }^{26}$

Así las cosas, Guatemala pudo recordar lo que sucedió, pudo encontrar respuestas a sus interrogantes, pero también tuvo que olvidar, porque la oscilación, al igual que las confrontaciones bélicas, puede ser muy violenta y por eso se debe olvidar. ¿Pero cómo puede algo semejante olvidarse?, ¿para qué recordó Guatemala si después tiene que olvidar?, ¿dónde y cómo empieza el olvido? En el próximo apartado pretendemos dar unas respuestas aproximadas a estas interrogantes.

\section{Con Pasión Absoluta: o un texto entre la memoria y el olvido}

La escritura en Centroamérica necesita ser reconocida por instancias supremas que la autoricen, que le permitan ser para que, después, la literatura sea; la lógica de la premiación responde a la asignación de un lugar desde el cual la literatura centroamericana puede ser movilizada; si no existe movilización, entonces no existe literatura, entendiendo esto por la respuesta que el lector, o público, le atribuye al texto. ${ }^{27}$ De modo que el premio permite que el libro circule, pero no garantiza que el texto se movilice, es una trampa que atrapa a todo aquel que cree que en el premio está la certeza de una buena propuesta ${ }^{28} \cdot{ }^{29}$ No obstante, la trampa del premio está no en la pomposidad de su premiación misma, sino en la consecuencia implícita: por lo general, los honores se olvidan fácilmente.

En el caso de Con Pasión Absoluta nos encontramos un texto premiado para que lo

\section{$26 \quad$ Ibid,. 22.}

27 Redacción Cultura, “Anuncian premio Monteforte”, Prensa Libre, Revista Buena Vida. Pág. 57, Guatemala, 2005. jueves 20 de enero de 2005.

28 Arturo Monterroso, "Con Pasión Absoluta. Máquina del tiempo". elPeriódico, Guatemala, 2005, 13 de noviembre.

29 A.L, Ola, “Con Pasión Absoluta” Siglo XXI, Vida. Pág. 2, Guatemala, 2005, miércoles 26 de enero. 
olvidaran inmediatamente después, y ese olvido se hace en varios sentidos: el primero, desde el sentido de la edición del libro, y el segundo, desde la crítica misma, o en otras palabras, desde la experiencia de lectura de aquellos que pueden escribir en periódicos gobiernistas ${ }^{30} .^{31}$

Por lo que toca a lo primero, y a partir de la dinámica del estructuralismo en la literatura, el texto es recuperable por pedazos, así como la memoria de Guatemala. El centro de la trama lo constituyen todas las formas de recordar dentro de la novela, recuerdos circunscritos a la vida de tres mujeres y, consecuentemente, la alternancia de recuerdos personales con hechos de la historia política guatemalteca. El resto, incluyendo el desafortunado capítulo diez de la novela, parece responder a una necesidad de editorial y de ventas, es decir, pareciera como si el texto hubiese sido redimensionado, como distraído, del grueso de su contenido, acuerpando esa redimensión con una portada y un título que, como falacia de imagen, suponen una trampa en el contenido, porque habría que preguntarse ¿para quién es la con pasión absoluta?, ¿por qué el cambio del título?, preguntas triviales sí, pero de la duda nace la aprehensión (ignorancia no es hacer y hacer preguntas, sino creer que se tienen todas las respuestas). El texto, en su escritura, reaviva la oscilación de la memoria guatemalteca: presenta detalles importantes que nacen del examen de la información existente y no de un afortunado recuento de memoria personal ${ }^{32}$. Tal tarea es prácticamente imposible.

Son esos detalles, fincas cafetaleras; expansión del cultivo del banano; Cabrera, Arbenz,

30 JC. Lemus, "Carol Zardetto. Premio centroamericano de novela: 'Mario Monteforte' " Prensa Libre, Cultura, Guatemala, 2005, martes 25 de enero, Pág. 41.

31 Redacción elPeriódico. "Con Pasión Absoluta". elPeriódico, Actualidad/Cultura. Guatemala, 2005, enero.

32 M. Ávila, "Memoria como escritura e inscripción para-históricas del sujeto mujer en 'Con pasión absoluta', de Carol Zardetto", Ciudad de Guatemala, s.a. Disponible en: http://www.fygeditores.com/fgconpasion.htm (Fecha de ingreso: 18 de agosto de 2007). 
Ubico, Ríos Montt, etc., los que consienten en la expansión del texto, en su ebullición; son esos pormenores los que hacen que el texto sea releído, una y otra vez, pues su sentido pluraliza los sentidos suscitados por la experiencia de lectura: nada más inverosímil que lo verosímil se vuelva inverosímil. En esas particularidades, el lector queda atrapado y busca que, la referencialidad de la historia guatemalteca, sea reafirmada y estudiada, es decir, que obliga a una indagatoria sobre aquello de lo que no fue posible hablar en Guatemala durante tanto tiempo; el juego de la escritura, la oscilación en los paratextos, es otra forma que proporciona garantía a ese recordar: las notas, los párrafos, los marcos en los párrafos, etc., representan ese ir y venir en la escritura que hace de la divagación un espacio cada vez más sólido en su estructura.

Ante ese concierto, podemos agregar que el ejercicio de escritura involucra, justamente, dos movimientos: por un lado, la praxis de una grafía compleja y, por otro, todo el verter de significados posibles, voluntariosos todos que permiten la composición armoniosa en textos que, en un inicio, parecen no advertir nada, pero que con el progreso de una lectura acompasada, parsimoniosa o desinteresada, obligan a releer. Este último gesto de la lectura solo es posible cuando algo no queda claro, y eso que no queda claro nos sorprende porque lo hemos pasado por alto, o en otras palabras, lo hemos olvidado.

Esta capacidad del escritor se traduce en la reversión de una anamorfosis que nace de una solicitud unánime: rechazarla para volverla a formar, de modo que lo que se reforma es el producto de una apología entre una fabricación irreal y una composición (¿la de la escritura?). Con esto suponemos que plantear ingenuamente qué es un recuerdo, es llevar lo onírico a un desplazamiento absoluto y total sobre la escritura, sin cambios, sin dejar nada; pretender tal empresa es, con mucho, el resultado de una pobre recomendación nacida de un recetario que ubica a esa capacidad en el absurdo de empalagosas nimiedades de belle indiferent ${ }^{33}$.

33 Segovia, G. “Apasionada de las letras”. Prensa Libre, Buena Vida: Cultura. Pág. 57, Guatemala, 2005, 
Todo lo contrario, cuando se rechaza la ameba mental y luego se la proyecta sobre líneas consecutivas en, digamos, una constitución de sentido infinito, tenemos, como resultado, la proyección de espectros que versan en la posibilidad de exorcizar a otros: al escritor y al lector. Estos ya no importan, solo queda el texto, su contenido o, en otras palabras, el resultado de una proyección, proyección exclusiva del lector que, por su neurotiliteratura, rechaza el texto, para releerlo, para exorcizarlo, para olvidarlo. Esa es, desde la literatura, la riqueza del texto Con Pasión Absoluta no las bagatelas de Irene, que corresponden a la reincidencia en el tema del ‘eterno platónico’ característico de la novela rosa.

Sin embargo, poco o mucho podremos lograr con esta apreciación, pues el texto desde eso que llaman crítica, aspecto que planteamos como segundo sentido, está ubicado en una recuperación de la protagonista y 'el modo de ser la mujer guatemalteca', y censura toda referencialidad a su contenido histórico

La novela transcurre entre la reflexión, la descripción de lugares y estados de ánimo (...) de la producción de café, de la United Fruit Company, de la exhumación de osamentas en Comalapa, de la intervención estadounidense, de las jornadas de los estudiantes en los años 60, que aunque aportan la materia prima para construir un ingenioso contrapunto, son innecesarios porque la novela, con sus ágiles e inesperados saltos de tiempo, lugar y circunstancias no los necesita. La verdadera novela, la verdadera narración que fluye sin obstáculos es la historia de la vida de Irene, la protagonista, y de los seres humanos vinculados a ella, no el recuento histórico de nuestras calamidades aunque tengan toda la validez del mundo. Lo destacado en negrita es nuestro. ${ }^{34}$

jueves 20 de enero.

34 Arturo Monterroso, "Con Pasión Absoluta. Máquina del tiempo". elPeriódico, Guate- 
Toda su composición, que como tejido puede cortarse y extraer el tuétano, está subordinada a la doxológica recomendación de buscar en las palabras de la autora lo que ésta quiso decir, sentir o pensar, como si ésta pudiera recuperar todo lo que vertió sobre las hendiduras. De modo que la novela Con Pasión Absoluta queda sujeta a la autorización que el poder le administra para ser leída desde los encargos que hace la crítica. Muy interesante, pues es la crítica la misma que dice lo que debe olvidarse y por qué debe olvidarse.

Pareciera que este ejemplo de la novela actual guatemalteca, quizás como la del resto de Centroamérica en temas similares, está muy lejos de librarse de la miopía erudita que exige tales recomendaciones. Aún se concibe al escritor como el ser que sabe; todavía se justifica con el criterio de ficción cualquier elaboración y todos los ejercicios que permite la literatura, es decir, leer y escribir y cada una de las experiencias que esta genera, quedan excluidos. Es más, la novela centroamericana actual necesita de la teorización -me refiero a las recientes- de las universidades extrajeras para responder a sus preguntas, como si esta -la propia novela- no pudiera elaborarlas.

Desafortunadamente, Centroamérica sigue buscando afuera lo que ya tiene adentro, subestima su propia capacidad y sigue creyendo en la vieja fórmula del amparo externo, por eso, necesita de premios y de insignias, Centroamérica necesita que la alaben y que le digan que todo está bien y la novela Con Pasión Absoluta es una víctima más de esa conversión, cuando -a nuestro parecer- es una novela que ve a Guatemala por el revés del güipil: haciendo que lo que está al reverso sea más fascinante que lo que está en el anverso, y no la eterna glorificación de una escritora, o escritor, cualquiera que sea su nombre, que resulta innecesario.

mala, 2005, 13 de noviembre. 


\section{Conclusiones}

De manera muy puntual, podemos finalizar este primer estudio sobre la memoria y olvido, el caso de una novela guatemalteca, estableciendo lo siguiente:

1. Existen muchas definiciones de memoria: la histórica, la política, la social, la psicológica, la biológica, etc., pero la que nos interesa promover es la que nos propone la literatura, específicamente, la oscilación de la memoria entre el recuerdo y el olvido y, con ello, sometemos a examen la novela Con Pasión Absoluta, porque nos parece de mayor provecho trabajar con los intersticios que este texto expone.

2. El texto revela la oscilación en ese constante ir y venir del relato; sin menospreciar la trascendencia en la vida anímica de los personajes, consentimos en que el texto refleja la ubicación de memoria y olvido en el tanto que, desde su escritura, la novela nos muestra, de manera clara, esa oscilación.

3. Como en la Teogonía, la Memoria y el Olvido es una lucha de titanes que no concuerda nunca; estas dos manifestaciones asisten al concierto promovido por instancias superiores, pero ese recordar conlleva el riesgo de tocar nombres, apellidos, hechos concretos que solo perjudican a los mismos que incitan a la recordación.

4. La memoria y el olvido, en Guatemala, solo permitió a los propios guatemaltecos finiquitar asuntos que han repercutido en sus vidas. Textos, como el que estudiamos, permiten adentrarnos en una historia que sólo compete a las víctimas directas, porque con la misma intención con que se origina su divulgación, con esa misma intención se obliga al texto a ser leído de una forma, es decir, se orienta al lector a hacer una lectura de sus protagonistas, pretendiendo que omita hechos relevantes en la historia de un país, 
de su propio país.

5. La novela actual centroamericana atraviesa por una disyuntiva importante: conformar su creación desde el espacio de la elaboración de formas nuevas, experimentales, o someterse a la revisión de su pasado y sustraer todo el material posible para trasladarlo a la escritura. El problema radica en no hacer lo uno o lo otro, sino en sostener que esa dinámica revitalice la narrativa centroamericana haciendo nuevas y mejores propuestas.

6. La “memoria histórica" no puede nunca ser considerada un instrumento de control político, sin embargo, parece que sí es posible hacerlo, eso solo consigue alcanzar metas nefastas, y se advierte que cualquier tipo de totalitarismo, el que sea, siempre es peligroso, pues la verosimilitud guiada hacia la inverosimilitud puede cometer el error de dejar intersticios subversivos por donde la escritura y la lectura aprehendan el vaivén de la memoria y el olvido de los pueblos. 